\title{
أسلوب الأمر وتعليمه للناطقين بغير اللغة العبية
}

Ira Aniati

iraaniati@iain-padangsidimpuan.ac.id

Dosen Bahasa Arab IAIN Padangsidimpuan

التجريل

في بلدنا إندونيسيا يشعر بعض الطلاب بالصعوبات على فهم وتطبيق اللغة البلاغية عامة وأسلوب

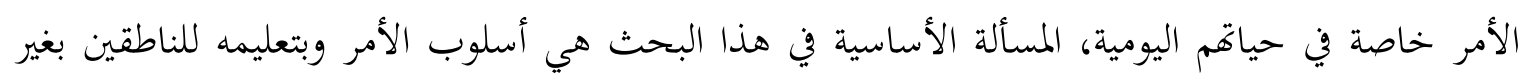

اللغة العربية. الهدف من هذا البحث هي لبيان أسلوب الأمر وبتعليمه للناطقين بغير اللغة العربية. المنهج

الذي تستخدمة في هذا البحث هو المنهج الوصفي. ووفي هذا البحث تستخدم الباحثة البحث المكتبي.

ونتائج البحث هي أساليب الأمر أربع صيغ. وهي فعل الأمر، والمضارع المقرون بلام الأمر، واسم فعل الأمر،

والمصدر النائب عن فعل الأمر. والمعانى البلاغية التي تخرج إليها صيغة الأمر كثيرة لايمكن حصرها. ومنها:

الإرشاد، والدعاء، والالتماس، والتمنى، والتغيير، والتسوية، والتعجيز، والتهديد، والإباحة. ويمكن استخدام

طرق التدريس المتنوعة في تدريس الأمر، وعلى المدرس أن يحسن اختيار الوسيلة الملائمة لطبيعة المادة التي

يدرسها، والتقييم بالاختبارات الشفوية والاختبارات الكتابية.

الكلمة المفتوحة: أسلوب الأمر؛ التعليم للناطقين بغير اللغة العربية

\begin{abstract}
Abstrak
Di Indonesia, sebagian siswa merasa sulit memahami dan menerapkan bahasa yang indah khususnya uslub amr dalam kehidupan sehari-hari, masalah penelitian ini adalah uslub amr dan pengajarannya bagi siswa non Arab. Tujuan penelitian ini adala untuk mejelaskan uslub amr dan pengajarannya bagi siswa non Arab.

Penelitian ini merupakan penelitian kualitatif dengan metode deskriptif. Dalam penelitian ini peneliti menggunakan penelitian kepustakaan. Hasil dari penelitian ini adalah ada empat bentuk amr, yaitu fi' $i l$ 'amr, mudhari' yang bersambung dengan lam al-amr, ism fi'il amr, dan mashdar pengganti fi'il amr. Adapun makna lain dari amr dalam kajian balaghah yaitu irsyad, du'a, iltimas, tamanni, taghyir, taswiyah, ta'jiz, tahdid dan ibahah. Berbagai macam metode dapat digunakan dalam pengajaran uslub amr dengan memilih media sesuai dengan materi yang dipelajari, begitu pula dengan penilaian dapat dilakukan dalam bentuk lisan ataupun tulisan.
\end{abstract}

Keyword: Uslub amr; Pengajarannya bagi siswa non Arab 
Thariqah Ilmiah: Jurnal Ilmu-Ilmu Kependidikan \& Bahasa Arab

Vol. 9. No. 1 Juni 2021

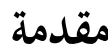
قد استخدم الناس اللغة بفطرتم وقد تحادث بينهم بقواعد البلاغة - كعلم من علوم العربية- لكي يقدروا على التواصل بالسلم والطلاقة ويسببوا الأثر في قلوب المخاطبين. كما أن البلاغة لهي تأدية المعنى الجليل واضحا بعبارة صحيحة فصيحة، لها في النفس أثر خلاب، مع ماءمة كل كلام للموطن الذي يقال فيه والأشخاص الذين يخاطبون.' للبلاغة العربية مصطلحات بلاغية، من علومها الثلاثة: البيان، والمعان، والبديع. وهذه المصطلحات البلاغية قد تعصب الطلاب على فهم الموضوع الذي يدرسونه، مع قلة تطبيقهم هذه المصطلحات في حياتم اليومية. وفضلا عن ذلك، يشعر بأهمية البلاغة عندما يترجم الجملة لأن فيها المعني المعجمي والمعني السياقي. وفي اليوم الحالي، البلاغة يفهمها المتخصصون فقط وأن بحث النصوص لأغراض التذوق البلاغي -والقرآن- لايتمكن من قيامه إلا من قبل الذين لمم مفردات اللغة العربية كثيرة والتراكيب النحوية كافة.

وإذا نظرنا إلى القرآن يتبين لنا أن للقرآن أساليبه المتنوعة، لكل منها مقام يقتضيه وغرض يناسبه، ومن تلك الأساليب المتنوعة هو الأمر. رأى أحمد الهاشمي أن الأمر هو "طلب حصول الفعل من المخاطب على وجه الاستعلاء مع الإلزام". ومثال ذلك، أمر الوالدة نخو ولدها في العبارة: "يا بنيّ اقرأ كتابك". فالأمر في هذه العبارة على وجه الحقيقة، يدل على أن الوالدة أعلى درجة من ولدها. وقد تخرج صيغ الأمر عن معناها الأصلي إلى معان أخرى تفهم من سياق

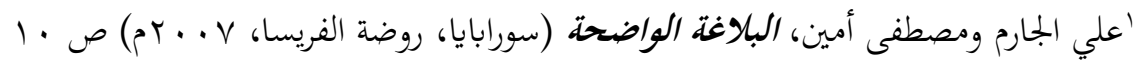


Thariqah Ilmiah: Jurnal Ilmu-Ilmu Kependidikan \& Bahasa Arab

Vol. 9. No. 1 Juni 2021

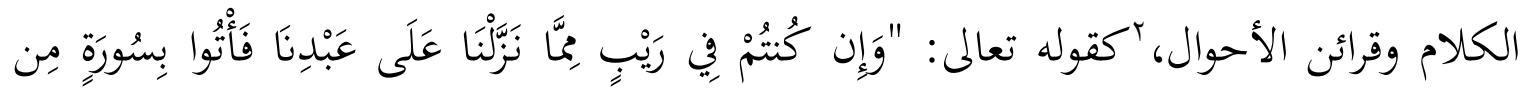

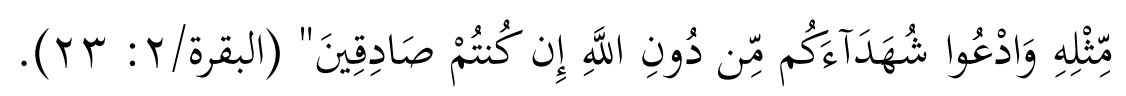

فليس من المعقول أن يكون الأمر في هذه الآية على حقيقته كما سبق، لأنه هيهات أن

يقدر العرب على الإتيان بسورة من مثل القرآن أو عدد من الآيات القرآنية، ولكن الأمر هنا

يخرج عن معناه الحقيقي إلى معنى التعجيز، أي بمعنى: "إظهار عجزهم من الإتيان بمثل سورة من

$$
\text { القرآن لأنه خارج عن طوقهم". }
$$

وفي بلدنا إندونيسيا يشعر بعض الطلاب بالصعوبات على فهم وتطبيق اللغة البلاغية

عامة وأسلوب الأمر خاصة في حياقم اليومية. لماذا؟ لأن للطلاب خلفيات تربوية مختلفة، وكان بعض الطلاب لم يتعلموا البلاغة من قبل، حتى يظن كثير منهم أن البلاغة عامة والأمر خاصة صعبة في تعلمها ويحتاج هذا العلم إلى الفهم العميق. ولذلك، أرادت الباحثة أن تقوم بالبحث عن أسلوب الأمر وما يتعلق بتعليمه للناطقين بغير اللغة العريبة لكي يشعر الطلاب بالسهولة في

$$
\text { تعلم وفهمه. }
$$

هذا البحث بحث كيفي. والمنهج الذي تستخدمه الباحثة في هذا البحث هو المنهج

الوصفي، والمنهج الوصفي يعتمد على دراسة الواقع أو الظاهرة كما توجد في الواقع ويهتم hal. 427

${ }^{2}$ Hifni Bek Dayyab, dkk, Kaidah Tata Bahasa Arab (Jakarta, Darul Ulum Press, 1991) cet. 3,

"أحمد باحميد، دوس البلاغة العربية الملدخل في علم البلاغة وعلم المعانى، (جاكرتا، PT. Raja Grafindo, 
Thariqah Ilmiah: Jurnal Ilmu-Ilmu Kependidikan \& Bahasa Arab

Vol. 9. No. 1 Juni 2021

بوصفها وصفا دقيقا يعبر عنها تعبيرا كيفيا أو كميا. ؛والمراد بالمنهج الوصفي هنا أن تبين الباحثة عن أسلوب الأمر وكيفية تعليمه للناطقين بغير اللغة العربية. في هذا البحث تستخدم الباحثة البحث المكتبي، وهو اعتماد الباحثة على قراءة الكتب المتنوعة والمتعلقة بموضوع البحث. ومن أهمها كتاب البلاغة الواضحة للشيخ علي الجارم ومصطفى أمين، وكتاب تعليم العربية لغير الناطقين بها مناهجه وأساليبه للأستاذ الدكتور رشدي أحمد طعيمة، وغير ذلك مما يؤكد هذا

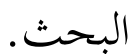

الأسلوب جمعه أساليب بمعنى الطريق: الفن من القول أو العمل.ْْ وقال علي الجارم

ومصطفى أمين "الأسلوب هو المعنى المصوغ في ألفاظ مؤلفة على صورة تكون أقبب لنيل الغرض المقصود من الكالام والأفعال في نفوس سامعيه. ج ورأى البلاغيون أن أسلوب الأمر نوع من أنواع الإنشاء الطلى ولا يتحدد على صيغة فعل الأمر فقط. و والأمر مصدر من كلمة (أمر، يأمر، أمرا وآمرَةً وإمارا): طلب منه فعل شيء أو انشاءَه فهو آمر وذاك مأمور. يقال "أمره الشيء وبالشيء". ₹ويعرف البلاغيون الأمر بأنه طلب حصول الفعل من المخاطب على وجه الاستعلاء

$$
\begin{aligned}
& \text { ؛ذوقان عبيدات وآخرون، البحث العلمي: فهمه، أدواته، أساليبه، (الرياض: دار السامة للنشر والتوزيع، } \\
& r \leqslant V \text { ص }
\end{aligned}
$$

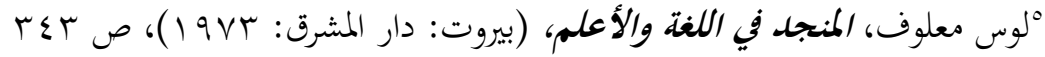

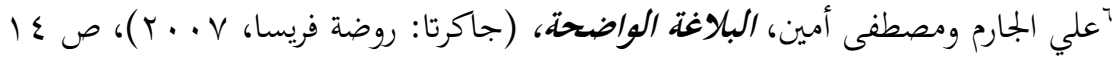

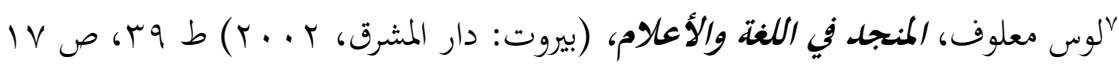


Thariqah Ilmiah: Jurnal Ilmu-Ilmu Kependidikan \& Bahasa Arab

Vol. 9. No. 1 Juni 2021

مع الإلزام.^ المراد بالاستعلاء هو "صدور الأمر ممن يكون أرفع منزلة ومقاما، أو ممن يدعي لنفسه منزلة أعلى ومقاما أرفع سواء أكانت تلك حقيقة أمره أم لم تكن". و وقسم عبده عبد العزيز قلقيلة الأمر على قسمين : الأمر الحقيقي والأمر البلاغي. فالأمر الحقيقي هو طلب الفعل على سبيل الاستعلاء والإلزام، 'اكقول الأم لولده الكبير: احفظ أخاك الصغير. هذا المثال يشتمل على صيغة يطلب بها على وجه التكليف والإلزام حصول شيء لم يكن حاصلا وقت الطلب، وطالب الفعل فيه أعظم وأعلى ممن يطلب منه. وأما الأمر البلاغي فهو "إذا اختل الشرطان السابقان كالاهما أو أحدها لم تدل صيغ الأمر على معانيها الحقيقة، وإنما تدل على معان بلاغية هتدى إليها بذوقنا وبسياق الكلام وقرائن الأحوال.'” ذهب البلاغيون على أن أساليب الأمر أربع صيغ. وهي فعل الأمر، والمضارع المقرون بلام الأمر، واسم فعل الأمر، والمصدر النائب عن فعل الأمر.

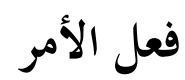
فعل الأمر هو "ما يطلب به حدوث شيء بعد زمان التكلم". باكقوله الوالد لولده: ذاكر دروسك، وقوله تعالى خطابا ليحي عليه السلام: "خذ الكتاب بقوة" (مريم: r I). وقد ^ أممد الهاشمى، جواهر البلاغة في المعاني والبيان والبديع، (إندونيسيا: مكتبة دار إحياء الكتب العربية،

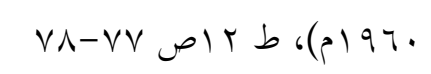

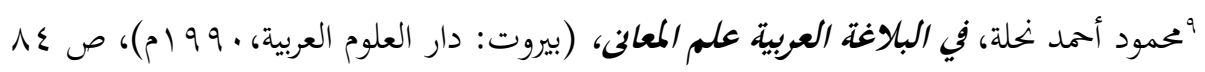

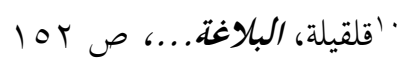

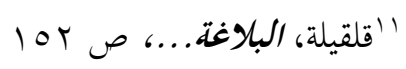

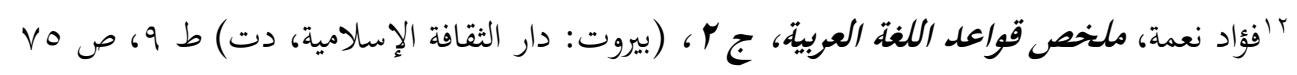


Thariqah Ilmiah: Jurnal Ilmu-Ilmu Kependidikan \& Bahasa Arab

Vol. 9. No. 1 Juni 2021

دل الطلب في هذين المثالين عل صيغة فعل الأمر. وقيل أن الأمر هو "ما دل على طلب وقوع

$$
\text { الفعل من الفاعل المخاطب بدون لام الأمر". با مثل: اجتهد وتعلّم. }
$$

فعل المضارع إذا اتصلت به لام الأمر يفيد بطلب وقوع الفعل وكان معناه فعل الأمر.

وقيل المضارع المقرون بلام الأمر هو "يطلب بها إحداث فعل". ؛' ولام الأمر مكسورة إلا إذا

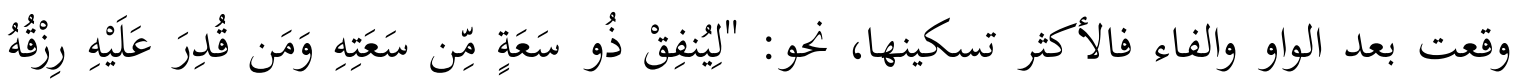

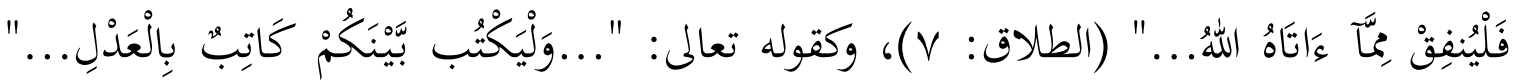

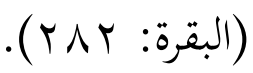

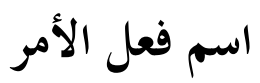

اسم فعل الأمر هو "اسم يدل على معنى فعل الأمر". •ا مثل آمين بمعنى استجب، وصه

بمعنى اسكت، وهيا بمعنى اسرع. ومن أسماء الأفعال ما هو في أصله ظرف وما هو مجرور بحرف.

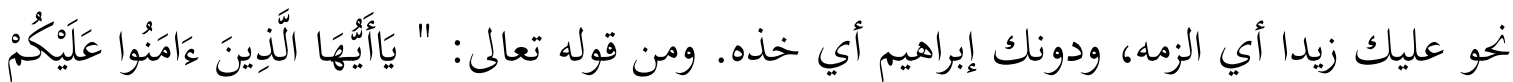

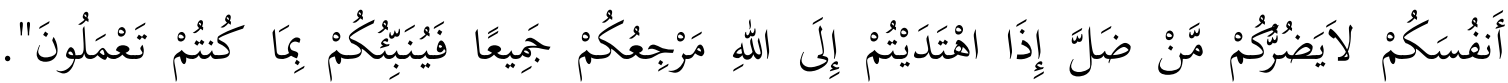

$$
\text { (المائدة: 0 ه 1 ) ف "عليكم" اسم فعل الأمر بمعنى الزموا. }
$$

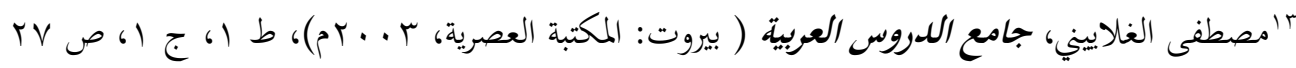

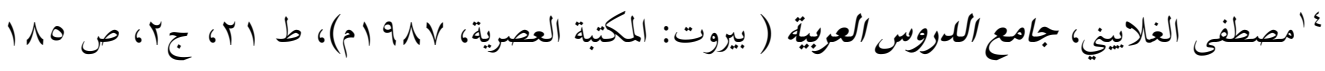

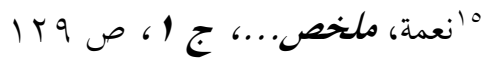


Thariqah Ilmiah: Jurnal IImu-Ilmu Kependidikan \& Bahasa Arab Vol. 9. No. 1 Juni 2021

$$
\text { المصدر النائب عن فعل الأمر }
$$

المصدر النائب عن فعل الأمر هو "ما يذكر بدلا من التلفظ بفعل الأمر". با نهو: على المصيبة التي أصابتك صبرا يعني اصبر على المصيبة التي أصابتك. ومنه قوله تعالى: "وََضَضَى رَبُّكَ

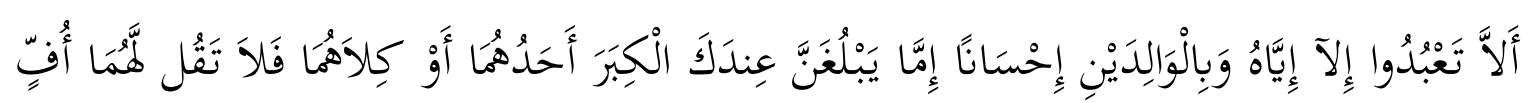

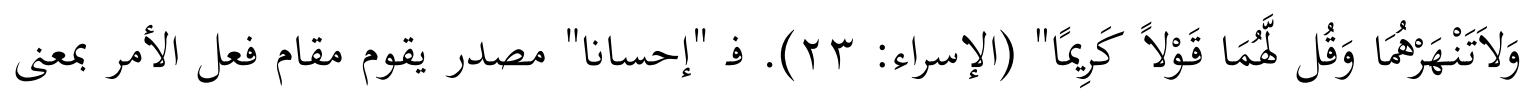
أحسنوا بالوالدين.

$$
\text { ب. المعاني البلاغية التي يخزج إليها أسلوب الأمر الحقيقي }
$$

وقد تخرج صيغ الأمر عن معناها الأصلي وهو طلب الفعل على وجه الاستعلاء والإلزام

إلى معان أخرى تستفاد من سياق الكلام وقرائن الأحوال. والمعانى البلاغية التي تخرج إليها صيغة

$$
\text { الأمر كثيرة لايمكن حصرها. ومنها: }
$$

الإرشاد وهو "طلب خلاء من كل تكليف وإلزام، يحمل بين طياته معنى النصيحة

والإرشاد". V' كقوله خالد ابن صفيان وهو من فصحاء العرب المشهورين لابنه: دع من أعمال السر ما لا يصلح لك في العلانية. فخالد بن صفيان لا يأمر ولده ولا يستعلى عليه ولا يلزمه. وإنما أراد أن ينصحه ويرشد عليه بأن يترك أعمال السر مادام لا يليق في العلانية.

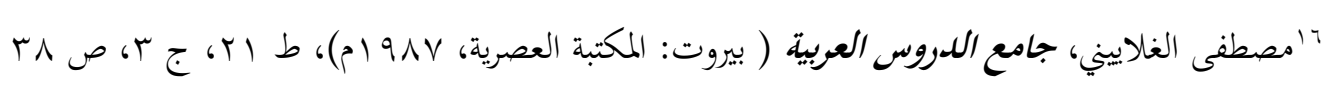

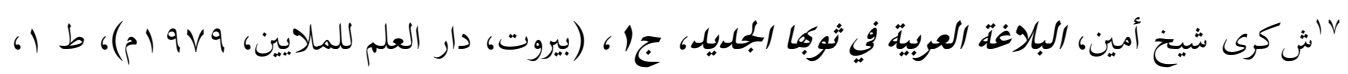


Thariqah Ilmiah: Jurnal Ilmu-Ilmu Kependidikan \& Bahasa Arab

Vol. 9. No. 1 Juni 2021

الدعاء وهو طلب الأدنى إلى الأعلى، والصغير إلى الكبير، والضعيف إلى القوي،

والمخلوق إلى الخالق. وقيل: والمقصود بالدعاء " الطلب على سبيل التضرع والتوسل، ويصدر من الأدنى إلى الأعلى منزلة وشأنا". ^اكقول تعالى في القرآن الكريم: "وَإِذْ قَالَ إِبْرَاِيمُ رَبِّ اجْعَلْ

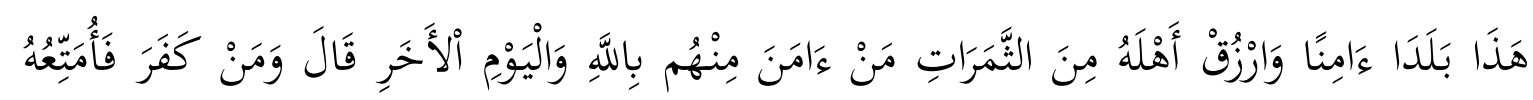

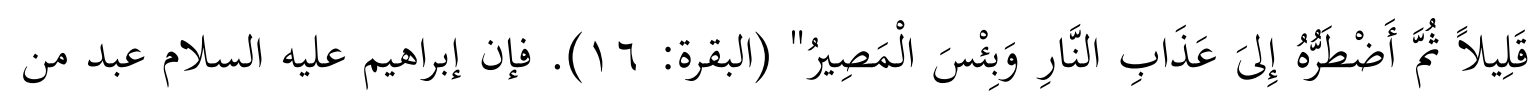
عباد الله. ولا يمكنه أن يأمر ربه أن يجعل هذا البلد يعنى المكة المكرمة بلدا أمنا ويرزق أهله من الثمرات. وإنما يقصد بالأمر هذا الدعاء، لأنه طلب على سبيل التضرع من المخلوق إلى خالقه. الالتماس الالتماس: ويكون لمن هو بمستوى القائل في الشأن نفسه، أو هو طلب الفعل الصادر عن الأنداد، والنظراء المساوين في المنزلة، والقدر.19 كقول الطالب لصاحبه: أعطني الكتاب من فضلك، فهذا الأمر يصدر من المتكلم إلى صاحبه الذي يماثله مقاما فلا استعلاء ولا إيجابا وإنما هو الالتماس.

التمنى التمنى وهو طلب أمر محبوب لايرجى حصوله. أما لكونه مستحيلا، وأما لكونه

ممكنا غير مطموع فيه، ويوجه فيه الأمر إلى غير العاقل، مثل: ليت الشباب يعود (مستحيل

$$
\text { حصوله).ليتي أملك دارا (غير مطموع فيه). 'r }
$$

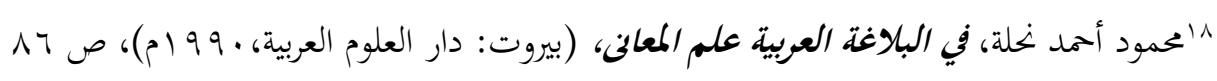

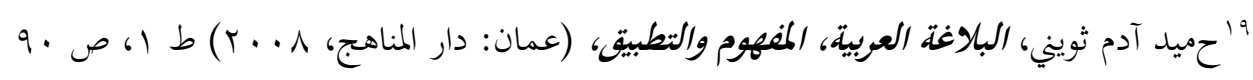

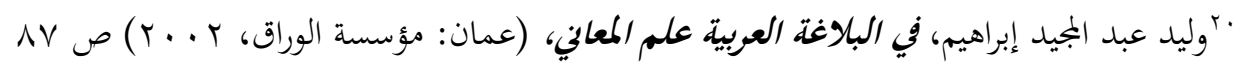


Thariqah Ilmiah: Jurnal Ilmu-Ilmu Kependidikan \& Bahasa Arab

Vol. 9. No. 1 Juni 2021

ويطلب المتكلم بالأمر شيئا محبوبا يرجو وقوعه ويكون الخطاب لغير العاقل، كقول امرئ

القيس " ألا أيها الليل الطويل ألا انجلى * بصبح وما الإصباح منك بأمثل".فامرئ القيس يطلب

من الليل الانجلاء والانكشاف وهو مما لا يصلح أن يوجه إليه خطابا فهو يتمنى أن ينتهى الليل بأحزنه وهمومه ويظهر له الصبح مشرفا جميلا. ولا يعقل أن يتوجه إلى الليل بأمر حقيقي لأن الليل لا يسمع ولا يطبع، وإنما أرسل صيغة الأمر وأراد بها التمنى.

التخيير وهو يتحقق إذا كان الأمر مقصودا به تخيير المخاطب بين شيئين أو أكثر مع عدم السماح له بالجمع بين هذين الأمرين أو بين هذه الأمور. 'بكقول بشار بن برد: "فعش واحدا أو صل أخاك فإنه * مقارف ذنب مرة وبجانبه". المراد بهذا القول، إذا أردت ألا يزال معك صديق فعش منفردا وذلك مستحيل، أما إذا أردت أن تعيش مع الناس فسامح إخوانك وصلهم على ما بهم من عيوب.

التسوية وهي عند ما يكون الملتقى في مقام يتوهم فيه أن أحد الأمرين أرجح من

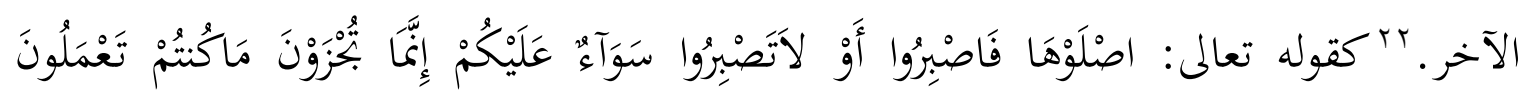
(الطور:7 1 ). فقد يتوهم المخاطب أن الصبر نافع فيدفع هذا التوهم بالتسوية بين الصبر والجزع. التعجيز وهو طلب أمر لا يقدر عليه المخاطب، ويدعي أنه يقدر عليه، لإظهار عجزه،

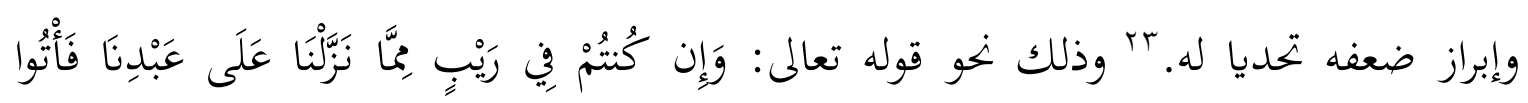

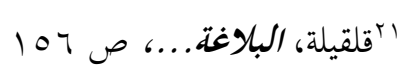

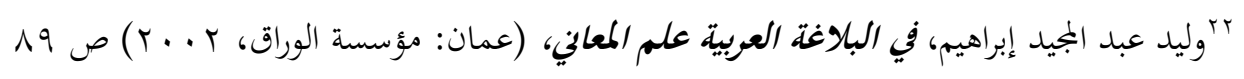

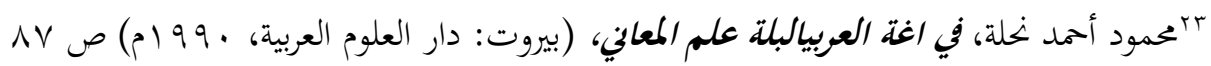


Thariqah Ilmiah: Jurnal Ilmu-Ilmu Kependidikan \& Bahasa Arab

Vol. 9. No. 1 Juni 2021

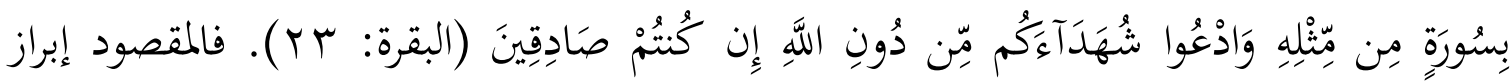
عجزهم عن الإتيان بسورة من مثل هذا القرآن، لأن ذلك خارج عن وسعهم وفوق طاقتهم.

التهديد وهو طلب أمر لا يرضي عنه المتكلم، وفيه وعيد للمخاطب به إن فعله، تخفيا له

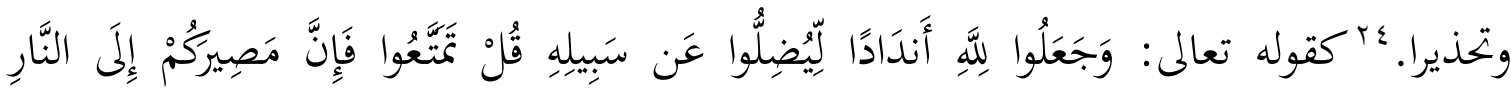
(إبراهيم: • ץ). فالأمر هنا ليس حقيقة. ولكن الأمر هنا للتهديد في مقام عدم الرضا بالمأمور ب.

الإباحة وهي تتحقق إذا كان المخاطب يتوهم أن المأمور به محظور عليه فيكون الأمر إذنا

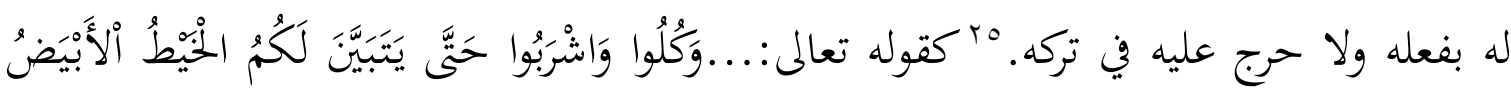

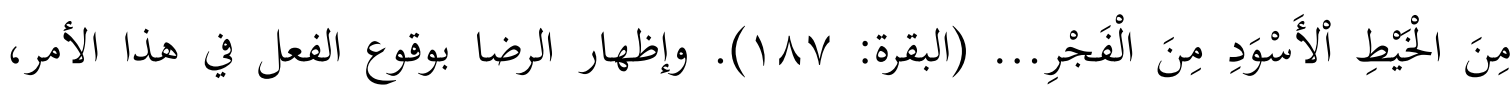

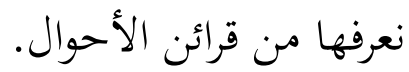

\section{ج. عملية تعليم أسلوب الأمر}

إن التعليم له علاقة وثيقة بالمنهج. والمنهج عنصر أساسي من عناصر العملية التعليمية، إن لم يكن صلبها. المفهوم القديم للمنهج: كان يقصد بالمنهج قديما المقرر الدراسي syllabus الذي يقدم للطلاب في مادة معينة. فهناك مقرر للجغرافيا، وهناك آخر للتاريخ، وثالث للرياضيات. ورابع للغة... وهكذا. بr ويتكون

$$
\text { NV گr }
$$

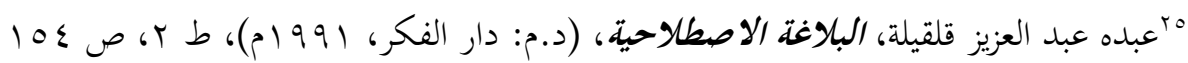

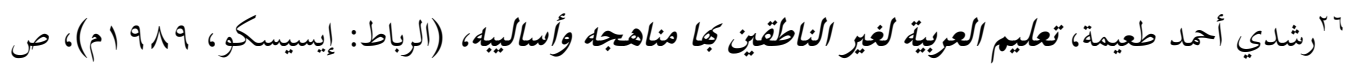


Thariqah Ilmiah: Jurnal Ilmu-Ilmu Kependidikan \& Bahasa Arab

Vol. 9. No. 1 Juni 2021

المنهج بمفهومه الحديث من أربعة عناصر أساسية هي: الأهداف التعليمية، والمحتوى، وطرق التدريس ووسائله، والتقويم وهو نحو التالي:.

طريقة تدريس الأمر : إن نجاح التدريس يتوقف على الطريقة من الطرق التي يستخدمها

المعلم عند القيام بعملية التعليم والتعلم في الفصل، واختيار الطريقة المناسبة دور هام لنجاح المعلم عند تقويم المواد الدراسية على تلاميذه.

ويمكن استخدام طرق التدريس المتنوعة في تدريس الأمر، منها الطريقة القياسية أو

الاستقرائية، وطريقة المحاضرة، وطريقة المناقشة، والطريقة الحوارية، والطريقة الانتقائية. أما الطريقة القياسية ففيها يبدأ المعلم الدرس بذكر القاعدة أو التعريف العام، وتوضيح القاعدة بعرض أمثلة لما، ثم التطبيق على القاعدة، وتستند هذه الطريقة على القياس، وهو انتقال الفكر من الحقائق العامة إلى الحقائق الجزئية، ومن الكل إلى الجزء، ومن المبادىء إلى النتائج، وأما الطريقة الاستقرائية ففيها يبدأ العقل من الخاص إلى العام، من الحالات الجزئية والمفردة إلى القواعد العامة التي تنتظم تلك الحالات المفردة. وفيها يحمل التلاميذ على كشف الحقائق وتعرفها متدرجين من الجزء إلى الكل، وفيها استخدام للأسئلة وصولا إلى استنباط القاعدة التي يراد تعليمها. ^r وطريقة المحاضرة، وهي في أحسن صورها عرض شفهى للمعلومات من جانب المعلم. وقد يكتفى في هذا الشرح بالكلمة المنطوقة، وقد يستعين ببعض الوسائل المعينة، أما الطلاب فهم Vاrممد مزمل البشير ومحمد مالك محمد سعيد، ملدخل إلى المناهج وطرق الثلديس، (الرياض: دار اللواء للنشر

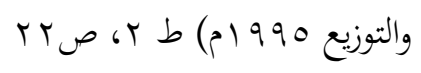

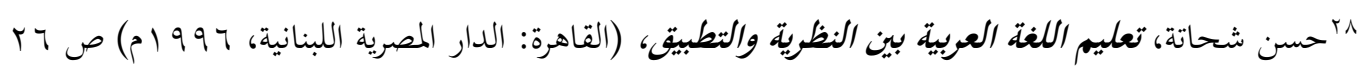


Thariqah Ilmiah: Jurnal Ilmu-Ilmu Kependidikan \& Bahasa Arab

Vol. 9. No. 1 Juni 2021

يستمعون، وقد يسجلون بعض ما يلتقطونه محا يلقى عليهم للرجوع إليه فيما بعد. ويلجأ المعلمون إلى هذه الطريقة، لأنها تمكنهم من عرض أكبر قدر من المعلومات في أقصر وقت مككن على أكبر عدد من الطلاب. أما المناقشة هي طريقة تقوم في جوهرها على الحوار. وفيها يعتمد المعلم على معارف التلاميذ وخبراهم السابقة، ويوجه نشاطهم بغية فهم القضية الجديدة مستخدما الأسئلة المتنوعة وإجابات التلاميذ لتحقيق أهداف درسه.

أما الطريقة الحوارية فهي طريقة الحوار والنقاش بالأسئة والأجوبة، للوصول إلى حقيقة من الحقائق. وتنسب هذه الطريقة إلى سقراط، ذلك الفيلسوف الذي كان يستعمل تلك الطريقة مع غيره متظاهرا بالجهل، ليرشد المتعلم حتى يصل إلى الحقيقة، بعد الأخذ والعطاء، والسؤال والجواب، في وقت بلغت فيه التربية العقلية في (أثينا) المركز الأسمى من العناية بها. وقد كان غرضه بث المعلومات في نفوس تلاميذ، وتعويدهم البحث وراء الحقيقة، حبا للحقيقة. وأما الطريقة الانتقائية فهي طريقة عرض مواد اللغة الأجنبية في القاعة الدراسية بأنشطة بجموعة متنوعة من عدة طرق تعليم، نخو أن تستخدم الطريقة المباشرة وطريقة القواعد والترجمة وطريقة القراءة في وقت واحد في الظروف التعليمية. ·َّيمكن أن يطبق المدرس هذه الطريقة في القاعة الدراسية بإعداد جيد وجهد خالص لتحقيق الأهداف المنشودة.

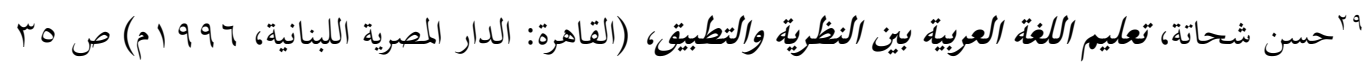
PT. Raja Grafindo Persada, 1995), hal 184 
Thariqah Ilmiah: Jurnal Ilmu-Ilmu Kependidikan \& Bahasa Arab

Vol. 9. No. 1 Juni 2021

الوسيلة التعليمية : الوسائل جمع من الوسيلة، وهي الأدوات التي يستخدمها المدرس أو

الطالب للمساعدة في تحقيق عملية التعليم والتعلم. 'ب وتبدو أهميتها من خلال إدراكي واقع وظيفتها، إذ تتيح للمتعلم أن يستخدم أكثر من حاسة واحدة في تعلمه. وهذا التعدد في استخدام الحواس يساعد على زيادة الفهم والاستدلال خاصة، وأها نوافذ المعرفة للإنسان، وكلما زاد عدد النوافذ المستقبلة سهلت وتحسنت وتعززت عملية التعليم والإدراك. وإن سوء اختيار الوسيلة أو الفشل في استعماها قد يحول دون تحقيق أهدافنا التربوية. ومن هنا على المدرس أن يحسن اختيار الوسيلة الملائمة لطبيعة المادة التي يدرسها، وأن يتدرب على استخدامها في الوقت المناسب، ثم لا يبالغ في استعماها. التقييم : التقييم هو الوسيلة التي نجمع بها الأدلة عن مدى صحة الفروض التي تستند عليها وتطبيقاتا التربوية، كما أنه وسيلة للحكم على كفاءة المدرس ومدى تعلم التلاميذ وتفاعلهم مع الخبرات التي يحتويها المنهج. بّ وهو أساس هام في العملية التعليمية لأن التقييم هو العملية التي يمكم بها المدرس من مدى نجاحه في تحقيق الأهداف التي ينشدها. وهناك أنواع كثيرة من الاختبارات اللغوية تختلف باختلاف وظيفتها ويمكن تقسيمها إلى قسمين: الاختبارات الشفوية والاختبارات الكتابية: الاختبارات الشفوية، وهي من أقدم أنواع الاختبارات استعمالا،

"آرشدي أحمد طعيمة ومحمد السيد مناع، تعليم العربية والدين بين العلم والفني، (القاهرة: دار الفكر العربي، ir rrr

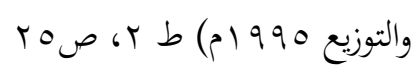


Thariqah Ilmiah: Jurnal Ilmu-Ilmu Kependidikan \& Bahasa Arab

Vol. 9. No. 1 Juni 2021

تعتبر الاختبارات الهامة لبعض المواقف، وتتناول جوانب معينة لا تعالجها الاختبارات الأخرى، فهناك بعض المهارات اللغوية لا يقيسها إلا الاختبار الشفوي. والمثال: أذكر مثالا من الأمر الحقيقي ومثالا من الأمر البلاغي. والاختبارات الكتابية (التحريرية)، تنقسم الاختبارات الكتابية إلى اختبارات المقال والاختبارات الموضوعية: الاختبار المقالي، تعد الاختبارات المقالية من أكثر أنواع الاختبارات استخداما في العملية التعليمية، وذلك لسهولة إعدادها من قبل المعلم. وتعرف الاختبارات المقالية بأها ذلك النوع من الاختبارات الذي يشتمل على عدد محدد من الأسئلة، والتي يطلب فيها من التلميذ الإجابة بمقال طويل يبين مدى حفظه أو استيعابه للموضوع الدراسي، ويعطي التلميذ الفرصة لكيفية عرض وتنظيم إجابته. والمثال: ما معنى الأمر من هذه

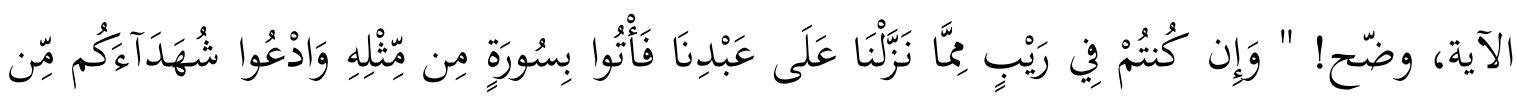
دُونِ اللَّهِ إِن كُتُمْ صَادِقِينَ (البقرة: rr)". والاختبارات الموضوعية، وفي إجابته على السؤال لا يحتاج التلميذ أن يكتب كثيرا. وتشمل الاختبارات الموضوعية عدة أنواع من بينها أسئلة الصواب والخطأ، والاختبار من متعدد وأسئلة المزاوجة وأسئلة التكميل. بّ والمثال من أسئلة الاختيار من متعدد: ... الباب قبل أن تدخل إلى الفصل! أ. إمسحب. أغلق ج. أطرق والمثال من أسئلة الصواب والخطأ: (ص-خ) إقرأ القرآن قراءة فصيحة! والمثال من أسئلة المزاوجة: ... الكتاب اللغة العربية! إمسح / إقرأ

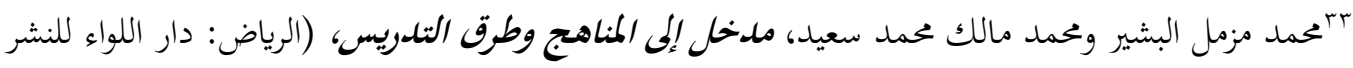

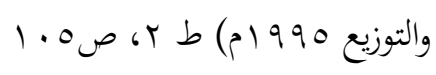


Thariqah Ilmiah: Jurnal Ilmu-Ilmu Kependidikan \& Bahasa Arab

Vol. 9. No. 1 Juni 2021

الخلاصة

قبل فاية هذا البحث يجدر للباحثة أن تقدم خلاصة عن أسلوب الأمر وتعليمه للناطقين

بغير اللغة العربية: - n

1. إن أساليب الأمر أربع صيغ. وهي فعل الأمر، والمضارع المقرون بلام الأمر، واسم فعل الأمر، والمصدر النائب عن فعل الأمر. وقد تخرج صيغ الأمر عن معناها الأصلي وهو طلب الفعل على وجه الاستعلاء والإلزام إلى معان أخرى تستفاد من سياق الكلام وقرائن الأحوال. والمعانى البلاغية التي تخرج إليها صيغة الأمر كثيرة لايمكن حصرها. ومنها: الإرشاد، والدعاء، والالتماس، والتمنى، والتغيير، والتسوية، والتعجيز، والتهديد، والإباحة. Y. يمكن استخدام طرق التدريس المتنوعة في تدريس الأمر، منها الطريقة القياسية أو الاستقرائية، وطريقة المحاضرة، وطريقة المناقشة، والطريقة الحوارية، والطريقة الانتقائية. وعلى المدرس أن يحسن اختيار الوسيلة الملائمة لطبيعة المادة التي يدرسها، وأن يتدرب على استخدامها في الوقت المناسب، ثم لا يبالغ في استعمالها. وهناك أنواع كثيرة من الاختبارات اللغوية تختلف باختلاف وظيفتها ويمكن تقسيمها إلى قسمين: الاختبارات الشفوية والاختبارات الكتابية. 
Thariqah Ilmiah: Jurnal Ilmu-Ilmu Kependidikan \& Bahasa Arab

Vol. 9. No. 1 Juni 2021

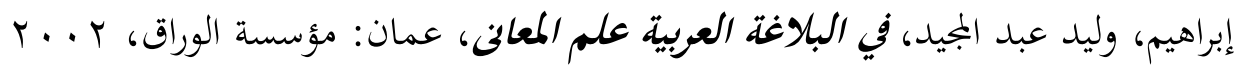

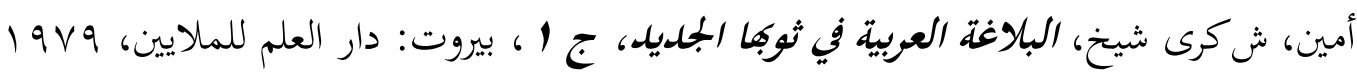

باحميد، أحمد، دور البالاغة العربية الملدخل في علم البلاغة وعلم المعانى، جاكرتا: PT. Raja

1997 Grafindo Persada

البشير، محمد مزمل، ومحمد مالك محمد سعيد، ملخحل إلى المناهج وطقق التلدريس، الرياض: دار

اللواء للنشر والتوزيع، 1990

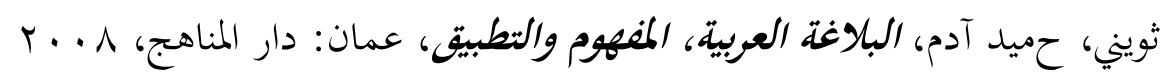

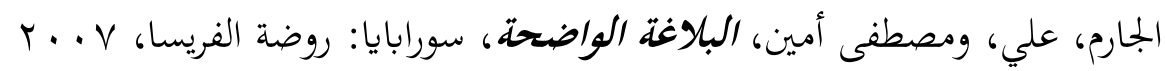

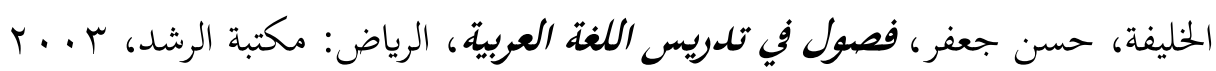

شحاتة، حسن، تعليم اللغة العربية بين النظرية والثطبيق، القاهرة: الدار المصرية اللبنانية، 1997

طعيمة، رشدي أحمد ، تعليم العربية لغير الناطقين بجا مناهجه وأماليبه، الرباط، إيسيسكو، 9 و 1 ا. طعيمة، رشدي أحمد، ومحمد السيد مناع، تعليم العربية والدين بين العلم والفني، القاهرة: دار

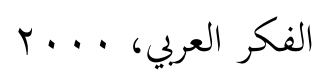

عبيدات، ذوقان، وآخرون، البحث العلمي مغهومه-أدواته-أساليبه، الرياض: دار السامة للنشر والتوزيع، 1999

الغلاييني، مصطفى، جامع الدروس العربية، بيروت: المكتبة العصرية، 1990 قلقيلة، عبده عبد العزيز، البلاغة الاصطلاحية، د.م: دار الفكر، 1991

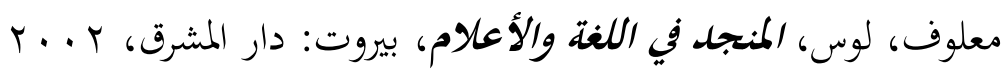
نحلة، محمود أحمد، في البلاغة العربية علم المعانى، بيروت: دار العلوم العربية، • 199 نعمة، فؤاد، ملخص قواعد اللغة العربية، ج ب ، بيروت: دار الثقافة الإسلامية، دت الهاشمي، أحمد، جواهر البلاغة في المعانى والبيان والبديع، إندونيسيا: مكتبة دار إحياء الكتب العربية، . 197 (19)

Dayyab, Hifni Bek, dkk. Kaidah Tata Bahasa Arab. Jakarta: Darul Ulum Press, 1991 Yusuf, Tayar dan Syaiful Anwar. Metodologi Pengajaran Agama dan Bahasa Arab. Jakarta: PT. Raja Grafindo Persada, 1995 